\title{
The correlation between sensory nerve conduction velocities and three metabolic indices in rats treated with streptozotocin
}

\author{
P.O.O.Julu \\ Department of Physiology, University College London, London, UK
}

\begin{abstract}
Summary. The fastest conduction velocities of the myelinated (A) and unmyelinated (C) sensory nerve fibres were measured in the saphenous nerves of rats made diabetic up to 5 weeks previously by injection of streptozotocin. The conduction velocity of the fastest A-alpha fibres in treated rats fell by $25 \%$ compared to control rats. The effect on the slow A-delta fibres was small but C-fibres were not affected. Levels of glycosylated haemoglobin, random plasma glucose, and the net changes in body weights were also measured. There were significant changes in these three metabolic indices among diabetic rats $(p<0.001)$ and the three indices
\end{abstract}

were inter-related. There was a good correlation between A-fibre conduction velocity and levels of glycosylated haemoglobin but no significant relationship between C-fibre conduction velocity and this metabolic index. A-fibre conduction velocity was statistically more correlated with levels of glycosylated haemoglobin than the other two metabolic indices $(p<0.01)$.

Key words: Diabetes, streptozotocin, A-fibres, C-fibres, conduction velocity, glycosylated haemoglobin, random plasma glucose, body weight.
It is now well established that peripheral nerve conduction velocity (CV) is slowed in experimental diabetes mellitus [1-4]. Of the various animal models used, motor nerve CV has been studied most. Data on sensory nerve $\mathrm{CV}$ in experimental models of diabetes include reduced sensory nerve $\mathrm{CV}$ in the dorsal spinal root [1], saphenous nerve [2], tibial nerve [5], sural and tibial nerves [6]. No detailed data on cutaneous nerve conduction velocity in experimental diabetes is available.

It is also now generally agreed that peripheral nerve conduction abnormalities occur in diabetic peripheral neuropathy in man [7-12]. It is interesting that sensory nerves respond rather differently to treatment compared with motor nerves. For example, vibratory threshold did not improve with short-term insulin therapy and yet motor nerve CV increased [13]; sensory action potential showed no improvement with insulin treatment while motor nerve CV increased [14]; sensory nerve CV did not improve with diet treatment in Type 2 (non-insulin-dependent) diabetic patients but motor nerve CV improved and correlated well with fasting plasma glucose concentrations [15]. Improvement in both sensory nerve CV and sensory action potential only began after intensive insulin treatment for a long period [16]. This unique response of sensory nerves to the treatment of diabetes, and the fact that the symptoms of diabetic neuropathy are mainly sensory [17], calls for a more detailed study of the sensory nerves especially in experimental models of diabetes where the different classes of fibres can be sampled easily.

This study was undertaken to provide some more data on cutaneous nerve CVs in streptozotocin-diabetes and to correlate these with three metabolic indices in order to throw light on the possible mechanism(s) leading to conduction abnormalities.

\section{Materials and methods}

\section{Experimental animals}

Thirty female Sprague Dawley rats were weighed, and 21 of them were chosen at random and treated with streptozotocin $(65 \mathrm{mg} / \mathrm{kg}$ in citrate buffer $\mathrm{pH} 5.6$ given i.p.). The others were given equivalent volumes of citrate buffer. Three groups of rats were investigated after one, two and five weeks of diabetes respectively. To have animals of nearly the same age (about 21 weeks old) at the time of CV determination, 21-week-old rats were used for 1-week and 2-weeks duration of diabetes, and 16-week-old rats were used for 5-weeks duration of diabetes. The age of rats at the start of this study was more than 14 weeks to avoid the variation of $\mathrm{CV}$ due to changing nerve water content [18]. The animals were kept in flat bottomed plastic cages, 


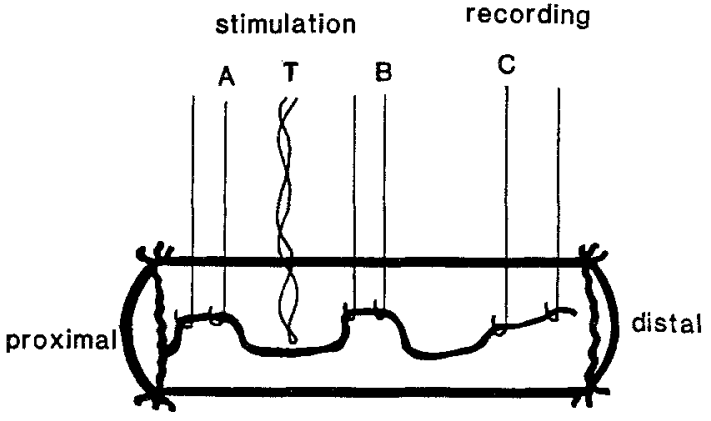

Fig. 1. Schematic representation of the in situ preparation of saphenous nerve for electrophysiological recording. There are two sets of stimulating electrodes, A and B, and one set of recording electrodes C. All are platinum wire electrodes. The thermocouple $\mathrm{T}$ monitors the temperature of the nerve segment between $\mathrm{A}$ and $\mathrm{B}$. This is the relevant segment for conduction velocity determination. The whole set up is in a pool of paraffin oil previously saturated with saline. The paraffin oil is held in a gutter formed by suturing the skin of the leg around a brass ring

fed with a diet containing $0.22 \%$ myo-inositol (Dixons Crane Mead Mills, London, UK), and given both food and water ad libitum. The animals were weighed initially and at the time of killing to estimate the net change in body weight.

\section{Electrophysiology}

The CVs were determined by an open method, where platinum electrodes were directly applied on the saphenous nerve in a pool of paraffin oil (Fig.1). The animals were anaesthetised using 25\% urethane (Sigma, London, UK) (1.25-1.5 g/ kg body weight) and supportive operations included carotid catheterisation for a continuous measurement of intra-arterial pressure, and trachaeostomy to reduce dead-space, for tracheal aspirations and for intermittent positive pressure ventilation if the need arose. Rectal temperature was maintained at $37 \pm 0.5^{\circ} \mathrm{C}$ using a thermistor and a negative feedback controlled table heater.

The skin of the leg was opened and sutured around a brass ring forming a gutter. About $5 \mathrm{~mm}$ of nerve was freed at three sites for the insertion of electrodes as shown in Figure 1. Two pairs of stimulating electrodes were inserted in the two proximal sites and a pair of recording electrodes were inserted in the distal site. The distal end of the nerve was then cut off to eliminate interference from the cutaneous receptors. It was therefore the antidromic impulses being recorded. This arrangement had a better signal-to-noise ratio because the recording electrodes were applied on the small, clean end of the nerve. The gutter was filled with paraffin oil previously saturated with normal saline to avoid nerve dehydration. Dry paraffin oil absorbs little water but can dehydrate a small nerve. The temperature of the pool nearest to the nerve segment relevant for $\mathrm{CV}$ determination was monitored by a thermocouple (Fig.1). With the rectal temperature maintained as mentioned above, the pool temperature was stable in both control and diabetic rats at (means \pm SEM) $37.3 \pm$ $0.30^{\circ} \mathrm{C}(n=8)$ among control and $37.1 \pm 0.22^{\circ} \mathrm{C}(n=16)$ among diabetic rats.

The nerves were stimulated by constant current pulses derived from a stimulus isolator (Neurolog, NL 800, Digitimer, Watford, UK) through a stimulus buffer (NL 510) and a rate generator (NL 303). The compound action potentials (CAPs) recorded through a high impedence headstage (NL 100) and an AC pre-amplifier and filters were output to a storage oscilloscope, a loudspeaker and a computer terminal. At the computer terminal the CAPs were digitised using a fast 8-bits analogue-to-digital converter (TSR3, Grafitek, Bristol, UK). The digitised signals were fed into a microcomputer (BBC micro model B, Acorn Computers, Cambridge, UK) for further processing and storage in floppy discs. The CAPs of the A-al-

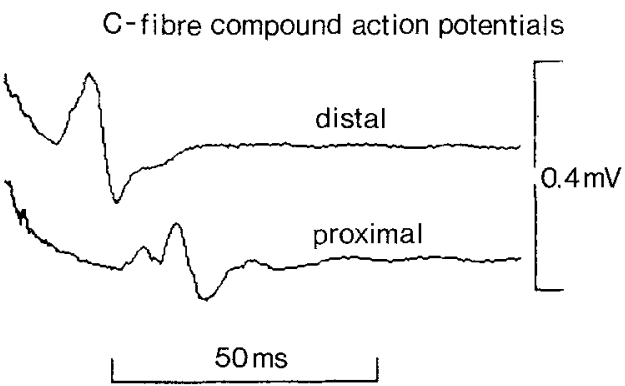

A-fibre compound action potentials

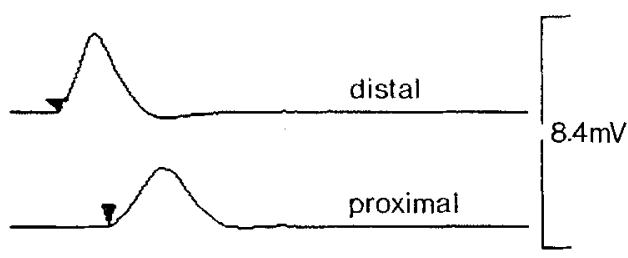

$1.25 \mathrm{~ms}$

Deita-fibre action potentials

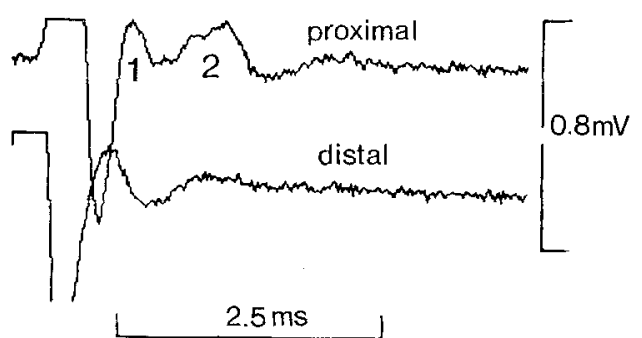

Fig. 2. Computer tracings of the compound action potentials (CAPs) of the three classes of nerve fibres in the rat saphenous nerve. A-fibre refers to the A-alpha-beta-fibres and delta-fibre refers to A-delta-fibres. Distal or proximal, refers to the sets of stimulating electrodes that generated the CAP (Fig.1). Single sweeps were used for the CAPs of A-alpha and A-delta fibres, but 10 sweeps were averaged from each set of stimulating electrodes in the case of C-fibres. The difference in the latencies in one set of CAPs is measured with the help of the two cursors (see A-fibre CAPs). The numbers 1 and 2 refer to the delta-one and delta-two elevations in the CAPs. Only deltatwo-fibre CAP is well separated from the negative after-potential of the A-alpha-beta-fibres

pha-beta fibres (A-fibres), A-delta-fibres (d-fibres) and C-fibres were recorded seperately as shown in Figure 2.

The three classes of fibres were discriminated during stimulation and recording of CAPs by the following methods: the thresholds of the three classes of fibres are different; the low threshold (up to $0.5 \mathrm{~mA}$ ) A-fibres were stimulated first, using stimuli of $50 \mu \mathrm{s}$ in width at $10 \mathrm{~Hz}$. Second to be stimulated were the d-fibres (with thresholds about twice those of A-fibres). Stimuli durations and frequencies were the same as for A-fibres. The high threshold C-fibres (about ten-fold those of A-alpha-beta fibres) were stimulated last. Stimuli each of $0.5 \mathrm{~ms}$ duration were given at $1 \mathrm{~Hz}$. Due to the differences in the CVs of the three classes of fibres, the oscilloscope and TSR3 sweep speeds were also used to discriminate the CAPs (see time scales in Fig.2). The time resolution of the TSR3 could be further improved under software control by displaying a fraction of the full cycle (sweep), one-eighth being the minimum fraction. Lastly, the differences in the amplitudes of the CAPs of the three classes of fi- 
bres allowed the oscilloscope and TSR3 sensitivity settings to improve the resolution of the smaller CAPs and to discriminate the larger CAPs (Fig. 2). For the C-fibres, to further improve the resolution 10 sweeps were averaged under software control.

For CV determination, stimulus strengths twice that of thresholds were used for all classes of fibres. CAPs from the two pairs of stimulating electrodes were recorded separately (Fig. 2). For A-alpha-beta and C-fibres, CVs $(\mathrm{m} / \mathrm{s})$ were calculated by measuring the length of nerve segment between the electrodes A and B (Fig. 1) to the nearest $0.5 \mathrm{~mm}$ and dividing it under software control by the difference in latency (ms) between the CAPs generated by the two pairs of stimulating electrodes. Delta-two-fibre (d2-fibre) CV was estimated using the conduction distance A-C and latencies of the CAPs generated by the proximal stimulating electrodes. This was because the seperation of the CAPs of these fibres from those of A-alpha-beta fibres could only be achieved sufficiently here. Only d2-fibre CV could be estimated in this set-up due to the same reason.

Data resulting from the analyses of the CAPs were stored in arrays accessible to a spread-sheet program written at University College London (Gardner-Medwin UCL, unpublished software) but modified by the author. This software calculated the CVs, rise-times of CAPs for the A-fibres, and performed all the statistical analyses according to the principles described in [19].

\section{Biochemistry}

Before killing the animal, $100 \mu \mathrm{l}$ of blood was aspirated from the carotid artery and diluted as 1 part of blood to 15 parts of a diluting fluid containing oxalate and fluoride ions to deactivate the enzymes of glycolysis. Erythrocytes were then separated, washed in saline at room temperature for $4 \mathrm{~h}$ and haemolysed with saponin (Corning Medical and Scientific, Palo Alto, Calif. USA). The proportion of glycosylated haemoglobin $\left(\mathrm{HbA}_{1}\right)$ was determined by electrophoresis as described in [20]. Random plasma glucose concentration was estimated from the supernatant using automated glucose oxidase method.

\section{Statistical analysis}

Data are presented as means \pm SEM. The parametric and unpaired $\left(t^{\prime}\right)$-test was used to test the significance of the difference in the means. This is different from Student's t-test because it allows the comparison of means of unpaired samples with different variances. Satterthwaite's approximate degree of freedom for this test was used together with Student's t-distribution to estimate the probability ( $p$ ) values [19]. Parametric linear regression analysis was carried out to estimate the correlation and regression coefficients and to test the significance of the linear relationships. The various groups were normalised by dividing the individual values by the mean of the control of that group, then covariance analysis was performed to test the significance of the difference in the regression lines. Analysis of variances in a multiple regression was used to test the relative significance of the three metabolic indices in the prediction of $\mathrm{CV}$. A difference with a degree of confidence more than $95 \%(p<0.05)$ was regarded as statistically significant.

\section{Results}

\section{Electrophysiological changes}

Compound action potentials. The magnitudes of CAPs varied a lot within both control and treated groups of nerves. There were however, no differences in shapes and amplitudes of CAPs between treated and control nerves in all the three classes of fibres studied. The am-
Table 1. Peak-to-peak amplitudes ( $\mathrm{mV}$. means \pm SEM) of compound action potentials of the various classes of saphenous nerve fibres studied

\begin{tabular}{lll}
\hline & All treated rats CAPs & All control rats CAPs \\
\hline C-fibres & $0.090 \pm 0.012(n=15)$ & $0.076 \pm 0.016(n=8)$ \\
$\mathrm{d}_{2}$-fibres & $0.095 \pm 0.016(n=12)$ & $0.233 \pm 0.102(n=6)$ \\
Alpha and & $4.2 \pm 0.7 \quad(n=16)$ & $4.4 \pm 1.2 \quad(n=8)$ \\
beta-fibres & &
\end{tabular}

a $\mathrm{CAPS}=$ compound action potentials; $\mathrm{SEM}=$ standard error of means. There were no significant differences between treated and control nerves. $\mathrm{d}_{2}$-fibres refers to A-delta-two-fibres

Table 2. Mean conduction velocity $(\mathrm{m} / \mathrm{s}, \pm \mathrm{SEM}$ ) for the various classes of saphenous nerve fibres

\begin{tabular}{llll}
\hline & $\begin{array}{l}\text { All } \\
\text { treated } \\
\text { rats }\end{array}$ & $\begin{array}{l}\text { All } \\
\text { control } \\
\text { rats }\end{array}$ & \\
\hline C-fibres & $\begin{array}{l}0.94 \pm 0.02 \\
(n=15)\end{array}$ & $\begin{array}{l}1.03 \pm 0.07 \\
(n=8)\end{array}$ & $\begin{array}{l}p<0.4 \\
(\mathrm{NS})\end{array}$ \\
$\mathrm{d}_{2}$-dibres & $\begin{array}{l}10.7 \pm 0.5 \\
(n=12)\end{array}$ & $\begin{array}{l}11.6 \pm 0.6 \\
(n=6)\end{array}$ & $\begin{array}{l}p<0.4 \\
(\mathrm{NS})\end{array}$ \\
& $35.2 \pm 1.3$ & $44.7 \pm 1.2$ & \\
A-fibres & $(n=16)$ & $(n=8)$ & $p<0.001$ \\
\hline
\end{tabular}

$\mathrm{SEM}=$ standard error of means, $p$ values indicate the significance of difference between the treated and control means, NS = not significant. $d_{2}$-fibres refers to the A-delta-two fibres, and A-fibres refers to the A-alpha-beta-fibres only. (see Fig. 3 for individual data)

Table 3. Summary of metabolic results

\begin{tabular}{lll}
\hline & $\begin{array}{l}\text { All } \\
\text { treated rats } \\
\mathrm{M} \pm \mathrm{SEM} \\
(n=16)\end{array}$ & $\begin{array}{l}\text { All } \\
\text { control rats } \\
\mathrm{M} \pm \mathrm{SEM} \\
(n=8)\end{array}$ \\
\hline $\begin{array}{l}\mathrm{dW}(\mathrm{g}) \\
\begin{array}{l}\text { Plasma glucose } \\
\left(\mathrm{mmol}^{\prime} /\right)\end{array}\end{array}$ & $-9.7 \pm 6.8$ & $14.9 \pm 4.1$ \\
$\% \mathrm{HbA}_{1}$ & $19.4 \pm 2.1$ & $7.0 \pm 1.3$ \\
\hline
\end{tabular}

$\mathrm{HbA}_{1}=$ glycosylated haemoglobin, $\mathrm{dW}=$ net change in body weight, $p<0.001$ for all the differences between treated and control means of the three metabolic indices. SEM $=$ standard error of means

plitudes ranged between $1.5-11.4 \mathrm{mV}$ among control and $1.5-11.5 \mathrm{mV}$ among treated nerves for A-fibres. They were $80-320 \mu \mathrm{V}$ among control, $80-200 \mu \mathrm{V}$ among treated nerves for $\mathrm{d}$-fibres. In $\mathrm{C}$-fibres they were $25-160 \mu \mathrm{V}$ among control and $30-200 \mu \mathrm{V}$ among treated nerves. A summary of the magnitudes is given in Table 1. Further analysis of the A-alpha-beta CAPs generated by the distal pair of stimulating electrodes gave similar rise-times for both control and treated nerves: (means \pm SEM) $180 \pm 7 \mu$ s $(n=8)$ among control nerves and $180 \pm 10 \mu s(n=16)$ among treated nerves.

Conduction velocity. The acute streptozotocin-diabetes slowed A-alpha-fibre CV to a greater extent compared 


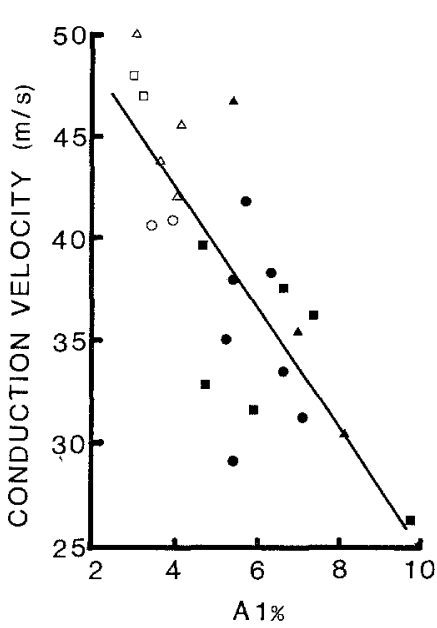

b

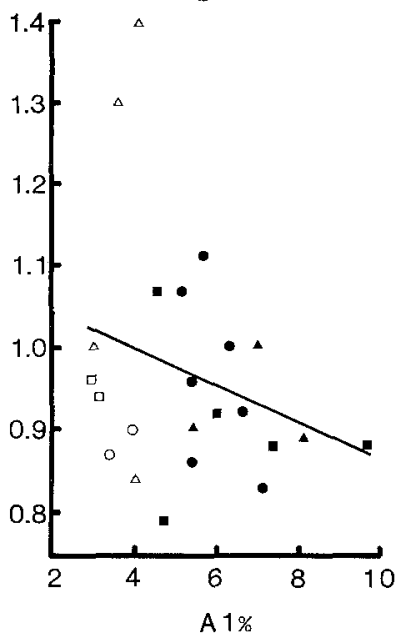

$\mathrm{C}$

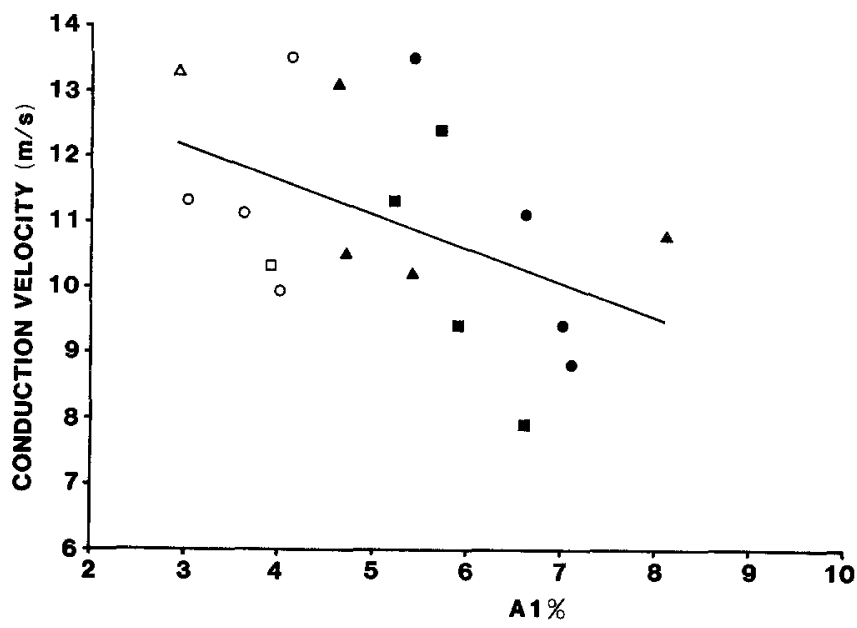

Fig. 3. Relationships between a the fastest A-alpha-fibre conduction velocity and glycosylated haemoglobin concentration showing a significant regression line $(r=0.8$ and $p<0.001)$, and $\mathbf{b}$ the fastest C-fibre conduction velocity and glycosylated haemoglobin concentration. The regression line shown is not significant $(r=-0.2$ and $p>0.2)$. e shows the conduction velocity of the fastest fibres in the delta-two group, also plotted against glycosylated haemoglobin levels. It has a significant regression line $(r=-0.5, p<0.05)$. A $1 \%=$ the percentage concentration of

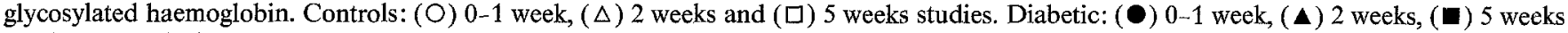
studies respectively

with the other classes of fibres. A-alpha-fibre CV ranged from $42.4-52.7 \mathrm{~m} / \mathrm{s}$ among control nerves but it was $29.4-47.8 \mathrm{~m} / \mathrm{s}$ among treated nerves. A-delta-fibre $\mathrm{CV}$ was $9.9-13.5 \mathrm{~m} / \mathrm{s}$ among control and $7.9-13.5 \mathrm{~m} / \mathrm{s}$ among treated nerves. For $\mathrm{C}$-fibres the range was $0.84-1.4 \mathrm{~m} / \mathrm{s}$ among control and $0.79-1.11 \mathrm{~m} / \mathrm{s}$ among treated nerves. The mean CVs are shown in Table 2 in which only the A-alpha fibres showed a significant difference $(p<0.001)$ in the two groups of animals, with a $25 \%$ reduction in the mean CV among streptozotocintreated rats. Individual CVs of the three classes of cutaneous fibres, from both streptozotocin-treated and control animals are plotted against $\mathrm{HbA}_{1}$ in Figure 3.

Table 4. Normalised relationships between the fastest conduction velocities and the various metabolic indices

\begin{tabular}{llll}
\hline & $\mathrm{RPG}^{\mathrm{a}}$ & $\mathrm{dW}^{\mathrm{b}}$ & $\mathrm{HbA}_{1}$ \\
\hline C-fibres & $r=-0.09$ & $r=-0.09$ & $r=-0.3$ \\
& $\mathrm{~b}=-0.01$ & $\mathrm{~b}=0.007$ & $\mathrm{~b}=-0.08$ \\
& $\mathrm{Sb}=0.03$ & $\mathrm{Sb}=0.02$ & $\mathrm{Sb}=0.06$ \\
& $p>0.5$ & $p>0.5$ & $p<0.4$ \\
$\mathrm{~d}_{2}$-fibres & $r=-0.5$ & $r=0.2$ & $r=-0.5$ \\
& $\mathrm{~b}=-0.06$ & $\mathrm{~b}=0.01$ & $\mathrm{~b}=-0.2$ \\
& $\mathrm{Sb}=0.03$ & $\mathrm{Sb}=0.02$ & $\mathrm{Sb}=0.07$ \\
& $p<0.5$ & $p<0.5$ & $p<0.05$ \\
A-fibres & $r=-0.5$ & $r=0.4$ & $r=-0.8$ \\
& $\mathrm{~b}=-0.06$ & $\mathrm{~b}=0.03$ & $\mathrm{~b}=-0.23$ \\
& $\mathrm{Sb}=0.02$ & $\mathrm{Sb}=0.02$ & $\mathrm{Sb}=0.04$ \\
& $p<0.025$ & $p<0.05$ & $p<<0.001$ \\
\hline
\end{tabular}

$r=$ correlation coefficient, $\mathrm{b}=$ regression coefficient, $\mathrm{Sb}=$ standard deviation of the regression coefficient. ${ }^{\mathrm{a}} \mathrm{RPG}=$ random plasma glucose concentration; ${ }^{b} \mathrm{dW}=$ net change in body weight, and $\mathrm{HbA}_{1}=$ glycosylated haemoglobin. $\mathrm{d}_{2}$-fibres refers to the A-deltatwo-fibres, and A-fibres refers to A-alpha-beta-fibres only. $p>0.05$ is not significant. Data were normalised by dividing individual values by the mean value in the control group

\section{Metabolic changes}

There were no significant differences in the net changes in body weights (dW), random plasma glucose concentrations, and the glycosylated haemoglobin levels $\left(\mathrm{HbA}_{1}\right)$ at different durations (1-5 weeks) within both streptozotocin-treated and control rats. For this reason, results were pooled together as "all control" or "all treated" rats as shown in all the Tables. Individual levels of $\mathrm{HbA}_{1}$ are plotted in Figure 3, but mean levels of all the three metabolic indices are shown in Table 3. Twenty-five percent of the treated rats gained weight, some as much as $25 \mathrm{~g}$. They also had low levels of hyperglycaemia, but only one rat was not glycosuric. The ranges for dW were 3-37g among control and $-85 \mathrm{~g}$ to $+25 \mathrm{~g}$ among treated rats. Plasma glucose ranged from $4.8-9.6 \mathrm{mmol} / 1$ among control and 8.1-32 mmol/1 among treated rats. The $\mathrm{HbA}_{1}$ levels were $2.9-4.1 \%$ among control and $4.6-9.7 \%$ among treated rats.

\section{Inter-relationships}

Within the metabolic indices. The three metabolic indices (random plasma glucose concentration, $\mathrm{HbA}_{1}$ and $\mathrm{dW}$ ) were inter-related. Using normalised data (see Statistical analysis in Methods), a significant linear relationship was obtained between plasma glucose and $\mathrm{HbA}_{1}$ with a regression coefficient $(\mathrm{b} \pm \mathrm{sb})$ of $1.4 \pm 0.2$ $(p<0.005, r=0.6)$. Where $\mathrm{b}=$ regression coefficient and $\mathrm{sb}=$ standard deviation of the regression coefficient. There was also a significant linear relationship between $\mathrm{dW}$ and plasma glucose with a negative regression coefficient of $-1.5 \pm 0.2 \quad(p<0.05$ and $r=-0.4$ ). A significant correlation was also obtained 


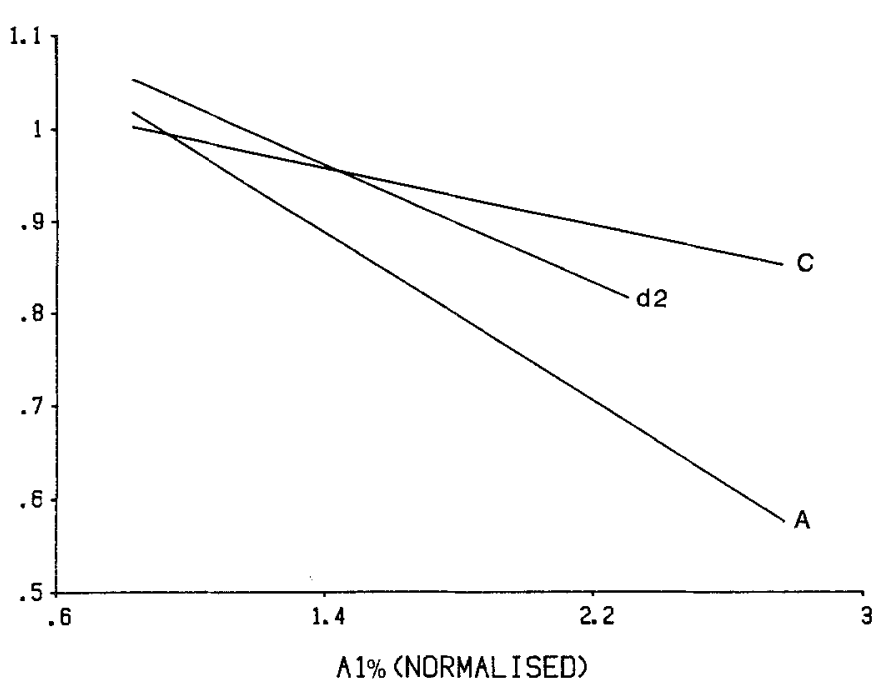

Fig.4. A comparison of the regression lines of the normalised relationships between the various conduction velocities and glycosylated haemoglobin concentration (see Statistical analysis for the method of normalisation). The myelinated fibres had significantly steeper regression lines compared with the unmyelinated fibres $(p<0.025)$. The regression line of the unmyelinated fibres is, however, not statistically significant $(p>0.2) . \mathrm{C}=\mathrm{C}$-fibres, $\mathrm{d} 2=$ delta-two-fibres, $\mathrm{A}=\mathrm{A}$ alpha-fibres and $\mathrm{A} 1 \%=$ percentage concentration of glycosylated haemoglobin

between $\mathrm{dW}$ and $\mathrm{HbA}_{1}$ with a negative regression coefficient of $-2.2 \pm 0.1(p<0.005$ and $r=-0.6)$.

Between the metabolic indices and $C V s$. Table 4 summarises the various inter-relationships studied. C-fibre $\mathrm{CV}$ had no linear relationship with any of the three metabolic indices, but A-delta fibre $\mathrm{CV}$ had a significant relationship with $\mathrm{HbA}_{1}$ only $(p<0.05)$. The A-alpha fibre $\mathrm{CV}$ however was significantly related with all the three metabolic indices $(p<0.025$ with plasma glucose, $p<0.05$ with $\mathrm{dW}$, and $p<0.001$ with $\left.\mathrm{HbA}_{1}\right)$. In the analysis of variances in a multiple regression of A-alpha fibre $\mathrm{CV}$ on $\mathrm{HbA}_{1}$, plasma glucose and $\mathrm{dW}$, the metabolic index most closely related with $\mathrm{CV}$ was $\mathrm{HbA}_{1}(p<0.01)$.

Figure 3 shows the fastest CVs of the three classes of cutaneous fibres, plotted against $\mathrm{HbA}_{1}$. When all the regression lines of the different cutaneous fibres were compared (Fig.4), the fastest A-alpha-fibre CV had a significantly different regression coefficient compared with the fastest C-fibre CV $(p<0.025)$. There was no statistical difference in the regression coefficients within the A-fibres (A-alpha, and delta-fibres).

\section{Discussion}

The acute streptozotocin-diabetes had different effects on the various classes of cutaneous nerve fibres studied. The fastest A-fibres were affected most followed by the thinly myelinated A-delta-fibres, but C-fibres were not significantly affected. One technical problem of determining the CV of the fastest fibres in the delta group is that the separation of these CAPs from that of A-alpha-beta fibres depends on desynchronisation which requires a long conduction distance. The rat saphenous nerve being of a limited length meant that only delta-two-fibre CAP was well separated. This was only when stimulated from the pair of electrodes with the longer conduction distance, the proximal electrodes. So only delta-two-fibre CV was measured using one pair of stimulating electrodes.

The inter-relationships within the metabolic indices and between them and CV are useful for drawing some inferences in this study. It is reassuring that after a statistical test, the three metabolic indices $\left(\mathrm{HbA}_{1}, \mathrm{dW}\right.$, and plasma glucose) commonly used in experimental diabetes were found to be inter-related. It is also interesting that $\mathrm{HbA}_{1}$ surpasses the other two in the prediction of slowed $\mathrm{CV}$ as proved by the multiple regression analysis (see also Table 4). Levels of $\mathrm{HbA}_{1}$ are only affected by the plasma sugar concentration, since the synthesis of $\mathrm{HbA}_{1}$ is non-enzymatic [21]; in cases where plasma sugar levels vary it will also depend on how long these levels stay high. Since non-enzymatic glycosylation of haemoglobin and other proteins occur even at normal plasma sugar levels, and streptozotocin has no known direct effect on this process except by elevating the plasma sugar concentration, all animals were pooled together in the test for the relationship between $\mathrm{HbA}_{1}$ and CV (Figs. 3 and 4). The plasma glucose was determined almost at the same time as the $\mathrm{CV}$, and yet it did not show a better relationship with slowed CV compared with $\mathrm{HbA}_{1}$. This weakens the arguments in favour of mechanisms which need acute accumulation of glucose in the nerve. A slow and cumulative process is more likely responsible for this $\mathrm{CV}$ alteration.

In the present study the distribution of the effect of streptozotocin-diabetes on CV suggests that saltatory conduction was more affected than continuous conduction. It is unlikely to be the effect of a generalised osmotic disorder of the nerves, for example the hypertonic effect of hyperglycaemia [22, 23] or sorbitol [24], because the unmyelinated nerves were not affected. Also a closer relationship between CVs and plasma glucose than with $\mathrm{HbA}_{1}$ or $\mathrm{dW}$ would be expected in such a situation. The myo-inositol and $\mathrm{Na}^{+}-\mathrm{K}^{+}$ATPase mechanisms $[3,4,25,26]$ were unlikely to be responsible for similar reasons. The latter two mechanisms are probably not important in the pathogenesis of diabetic neuropathy in distal cutaneous nerves in man [10], and in rats treated with streptozotocin [27]. Reduced $\mathrm{Na}^{+}-\mathrm{K}^{+}$ATPase activity leading to intracellular accumulation of $\mathrm{Na}^{+}$as suggested in [4], should cause a measurable reduction in the amplitudes of CAPs. There were no significant differences in the amplitudes of CAPs of all the classes of nerve fibres in this study. There was also no desynchronisation in the propagation of the CAP among streptozotocin-treated 
nerves as indicated by normal rise times and peak-topeak amplitudes. It is unlikely that a mechanism that involves various myelinated nerve fibres at different stages of either degeneration or conduction block was in operation.

Direct streptozotocin neurotoxicity was unlikely to be the cause of the CV alteration for the following reasons: rats which were given streptozotocin $(70 \mathrm{mg} / \mathrm{kg}$ body weight i.v.), but did not develop hyperglycaemia, had normal nerve CVs after 2 weeks [3]. In the same study, some rats which were given the same dose of streptozotocin developed hyperglycaemia, but the hyperglycaemia was rigorously controlled below $9 \mathrm{mmol} / 1$ with insulin; they also had normal nerve CVs at the end. This precludes direct streptozotocin neurotoxicity as a cause of slowed nerve $\mathrm{CV}$ in acute streptozotocin-diabetes. In the present study however, the lack of desynchronisation, the normal amplitudes of the CAPs, and the selective effect on the thickly myelinated nerve fibres are pointers against direct neurotoxicity. The close association between slowed nerve $\mathrm{CV}$ and $\mathrm{HbA}_{1}$ is also against the direct action of streptozotocin on the nerves because all the rats received the same single dose of streptozotocin; but levels of $\mathrm{HbA}_{1}$ were achieved through a cumulative process.

In a detailed and computerised morphometry using an electron microscope, the internodal myelinated axon's cross-sectional area and perimeter measured independently were unaltered in the saphenous nerve of streptozotocin-diabetic rats [27]. It is, therefore, unlikely that "axonal dwindling" $[28,29]$ was responsible for $\mathrm{CV}$ changes in this study. It would also be difficult to explain the differential effect of streptozotocin-diabetes on the nerve fibres in terms of "axonal dwindling".

An alteration in the electrical property of myelin was most likely the cause of this abnormality for the following reasons: The voltage dependent conductance of the nodes of Ranvier in this model of diabetes is normal [30], which rules out a change in the electrical properties of the nodes. A computerised morphometry of the nodes of Ranvier also showed normal nodal axollemal length and area in the saphenous nerves of streptozotocin-diabetic rats [27], which rules out any major changes in the dimensions of the nodes. Since there is no evidence to show that internodal axons are dwindling, it only leaves a change in the electrical property of myelin to explain the slowing of saltatory conduction.

The proposed change in the electrical property of myelin in the present study would have to be due to a cumulative process to explain the close association of $\mathrm{CV}$ with $\mathrm{HbA}_{1}$. Two such processes can be suggested: The extensive non-enzymatic glycosylation of the major structural protein $\left(\mathrm{P}_{\mathrm{o}}\right)$ of myelin [31] could add positive charges on the molecules [21]. This would polarise the molecules and increase the dielectric constant of myelin, which would increase the capacitance in the presence of a potential difference. Increased capaci- tance will slow down $\mathrm{CV}$ in proportion to the rate of variation of the potential difference with time [32], so the faster the initial CV the more this effect will show. This hypothesis would also explain the close association of $\mathrm{CV}$ with $\mathrm{HbA}_{1}$. A second possible mechanism is altered lipid composition of myelin, due to disordered metabolism of essential fatty acids in this model of diabetes [33]. This may also affect the electrical property of myelin. Essential fatty acid supplemetation has been shown to prevent the slowing of both motor nerve and sensory nerve CVs in streptozotocin-diabetes [34]. The manupulation of essential fatty acid metabolism may provide vital clues towards the pathophysiology of diabetic neuropathy since it is effective in both motor and sensory nerves in man [12] and streptozotocin diabetic rats [34].

These results indicate that the fastest $\mathrm{CV}$ of myelinated cutaneous nerve fibres were affected most by streptozotocin-diabetes. The process was related to the severity of hyperglycaemia as indicated by $\mathrm{HbA}_{1}$ levels. The unmyelianted sensory fibres were not much affected in this acute diabetes. The severity of streptozotocin-diabetes measured by $\mathrm{HbA}_{1}$, plasma glucose levels and $\mathrm{dW}$ is the same within the first 5 weeks. It was also evident that the three metabolic indices were inter-related, but $\mathrm{HbA}_{1}$ was the best index for the prediction of slowed nerve CV. It can be said that in streptozotocin-diabetic rats given both food and water ad libitum the net change in body weight is associated with the severity of the hyperglycaemia.

Acknowledgements. This study was carried out in University College London during the tenure of a Commonwealth Scholarship. I am grateful to the staff of the Department of Chemical Pathology, Middlesex Hospital, London for the assay of glycosylated haemoglobin.

\section{References}

1. Eliasson SG (1964) Nerve conduction changes in experimental diabetes. J Clin Invest 43: 2353-2358

2. Preston GM (1967) Peripheral neuropathy in alloxan-diabetic rat. J Physiol (London) 189: 49-50P (Abstract)

3. Greene DA, DeJesus PV, Winegrad AI (1975) Effects of insulin and dietary myoinositol on impaired peripheral motor nerve conduction velocity in acute streptozotocin diabetes. J Clin Invest 55: $1326-1336$

4. Sima AA, Lattimer SA, Yagihashi S, Greene DA (1986) Axo-glial dysjunction: novel structural lesion that accounts for poorly reversible slowing of nerve conduction in the spontaneously diabetic bio-breeding rat. J Clin Invest 77: 474-484

5. Hildebrand J, Joffroy A, Graff G, Coers C (1968) Neuromuscular changes with alloxan hyperglycemia. Arch Neurol 18: 633-641

6. Moore SA, Peterson R, Felten DL, O'Connor BL (1980) A quantitative comparison of motor and sensory conduction velocities in short- and long-term streptozotocin- and alloxan-diabetic rats. J Neurol Sci 48: 133-152

7. Lawrence DG, Locke S (1961) Motor nerve conduction velocity in diabetes. Arch Neurol 5: 483-489

8. Mudler DW, Lambert EH, Bastron JA, Sprague RG (1961) The neuropathies associated with diabetes: a clinical and electromyographic study of 103 unselected diabetic patients. Neurology 11: $275-284$ 
9. Kimura J, Yamada T, Stevland NP (1979) Distal slowing of motor nerve conduction velocity in diabetic polyneuropathy. J Neurol Sci 42: 291-302

10. Dyck PJ, Sherman WR, Hallcher LM, Service FJ, O'Brien PC, Grina LA, Palumbo PJ, Swanson CJ (1980) Human diabetic endoneural sorbitol, furctose, and myo-inositol related to sural nerve morphometry. Ann Neurol 8: 590-596

11. Greene DA, Brown MJ, Braunstein SN, Schwartz SS, Asbury AK, Winegrad AI (1981) Comparison of clinical course and sequential electrophysiological tests in diabetics with symptomatic polyneuropathy and its implications for clinical trial. Diabetes 30: $139-147$

12. Jamal GA, Carmichael H, Weir AI (1986) Gamma-linolenic acid in diabetic neuropathy. Lancet I: 1098 (letter)

13. Gregersen G (1968) Variation in motor conduction velocity produced by acute changes of the metabolic state in diabetic patients. Diabetologia 4: 273-277

14. Ward JD, Barnes CG, Fisher DJ, Jessop JD (1971) Improvement in nerve conduction following treatment in newly diagnosed diabetics. Lancet I: 428-431

15. Porte D, Graf RJ, Halter JB, Pfeifer MA, Halar E (1981) Diabetic neuropathy and plasma glucose control. Am J Med 70: 195-200

16. Reeves ML, Seigler DE, Ram Ayyar D, Skyler JS (1984) Medial plantar sensory response: sensitive indicator of peripheral nerve dysfunction in patients with diabetes mellitus. Am J Med 76: $842-846$

17. Thomas PK, Eliasson SG (1975) Diabetic neuropathy. In: Dyck PJ, Thomas PK, Lambert EH (eds). Peripheral neuropathy. Vol 2. Saunders, London, pp 956-981

18. Gabbay KH, Snider JJ (1972) Nerve conduction deficit in galactose fed rats. Diabetes 21: 295-300

19. Snedecor GW, Cochran WG (1982) Statistical methods, 7th edn. Iowa State University Press, Ames, Iowa, USA

20. Menard L, Dempsey ME, Blankstein LA, Aleyassine H, Wacks M, Soeldner JS (1980) Quantitative determination of glycosylated hemoglobin $A_{1}$ by agar gel electrophoresis. Clin Chem 26: 1598-1602

21. Bunn HF (1981) Nonenzymatic glycosylation of protein: relevance to diabetes. Am J Med 70: 325-330

22. Sugimura K, Windebank AJ, Natarajan V, Lambert EH, Schmid HHO, Dyck PJ (1980) Interstitial hyperosmolarity may cause axis cylinder shrinkage in streptozotocin diabetic nerve. J Neuropathol Exp Neurol 39: 710-721

23. Dyck PJ, Lambert EH, Winderbank AJ, Lais AA, Sparks MF, Karnes J, Sherman WR, Hallcher LM, Low PA, Service FJ (1981) Acute hyperosmolar hyperglycemia causes axonal shrink- age and reduced nerve conduction velocity. Exp Neurol 71: $507-514$

24. Gabbay KH (1973) The sorbitol pathway and complications of diabetes. N Engl J Med 288: 831-836

25. Greene DA, Yagihashi S, Lattimer SA, Sima AAF (1984) Nerve $\mathrm{Na}^{+}-\mathrm{K}^{+}$-ATPase, conduction, and myo-inositol in the insulindeficient BB rat. Am J Physiol 247: E534-E539

26. Gillon KRW, Hawthorne JN, Tomlinson DR (1983) Myo-inositol and sorbitol metabolism in relation to peripheral nerve function in experimental diabetes in the rat: the effect of aldose reductase inhibition. Diabetologia 25: 365-371

27. Julu POO (1986) The pathophysiology of peripheral neuropathy in acute streptozotocin induced diabetes mellitus in the rat. University College, London

28. Jakobsen J (1976) Axonal dwindling in early experimental diabetes. I. A study of cross sectioned nerves. Diabetologia 12: 539-546

29. Mattingly GE, Fischer VW (1985) Peripheral nerve axonal dwindling with concomitant myelin sheath hypertrophy in experimentally induced diabetes. Acta Neuropathol (Berl) 68:149-154

30. Jefferys JGR, Brismar T (1980) Analysis of peripheral nerve function in streptozotocin diabetic rats. J Neurol Sci 48: 435-444

31. Vlassara H, Brownlee M, Cerami A (1983) Excessive nonenzymatic glycosylation of peripheral and central nervous system myelin components in diabetic rats. Diabetes 32: 670-674

32. Jack JJB (1976) Electrophysiological properties of peripheral nerve. In: Landon DN (eds). The peripheral nerve. Chapman and Hall, London, pp 740-818

33. Faas FH, Carter WJ (1980) Altered fatty acid desaturation and microsomal fatty acid composition in the streptozotocin diabetic rat. Lipids 15: 953-961

34. Julu OOP (1987) The beneficial effect of essential fatty acid supplemetation in experimental diabetic neuropathy. In: Di Mario U, Fedele D, Micossi P (eds) Diabetic complications '87: international symposium. Rome, pp 60-63

Received: 29 December 1987

and in revised form: 16 February 1988

Dr. P.O.O.Julu

Department of Physiology

University of Zimbabwe

P.O.Box MP 167

Harare

Zimbabwe 